\title{
Validity of KAtex Test for the Diagnosis of Visceral leishmaniasis in Endemic Region of Bangladesh
}

\author{
Zakir Hossain Habib ${ }^{1}$, Afzalunnessa Binte Lutfor ${ }^{2}$, Sanya Tahmina Jhora ${ }^{3}$, Imtiaz Ahmed ${ }^{4}$, \\ Hasina Akhter ${ }^{5}$
}

\begin{abstract}
${ }^{1}$ Associate Professor, Department of Microbiology, Sir Salimullah Medical College, Dhaka, Bangladesh; ${ }^{2}$ Professor, Department of Microbiology, Ad-Deen Medical College, Dhaka, Bangladesh; ${ }^{3}$ Professor, Department of Microbiology, Sir Salimullah Medical College, Dhaka, Bangladesh; ${ }^{4}$ Associate Professor, Department of Microbiology, Sir Salimullah Medical College, Dhaka, Bangladesh; ${ }^{5}$ Assistant Professor, Department of Microbiology, Bangladesh Dental College, Dhaka, Bangladesh
\end{abstract}

[Received: 20 March 2014; Accepted: 15 April 2014; Published: 1 June 2014]

\begin{abstract}
Background: Early diagnosis of Kala-azar is of prime importance to reduce the transmission of the disease. Objective: The purpose of the present study was to evaluate KAtex test for the diagnosis of Kalaazar. Methodology: This cross sectional study was carried out in Department of Microbiology at Sir Salimullah Medical College, Dhaka for a period of one year from July 2007 to June 2008. Patients were selected clinically form all age and sex group hailing from endemic region of Mymensingh in a semi purposive manner excluding those who have already started taking medicine or refused to participate in the study. Blood and urine samples were collected from the patients admitted in Sir Salimullah Medical College, Dhaka, Mymensingh Medical College and Bhaluka Health Complex, Mymensingh. Result: Among 150 of the clinically selected patients, total 100 cases were confirmed to be positive for Kala-azar by rK39 ICT test. Age and sex matched 25 healthy persons each from endemic and non-endemic area was taken as control. Among the 100 sero-confirmed cases KAtex was positive in 87 (sensitivity of $87 \%$ ). Among the 50 controls none were positive by KAtex test resulting in specificity of these tests $100 \%$ and 98\% respectively. Conclusion: KAtex test has high sensitivity and specificity for the diagnosis of Kalaazar patients at endemic region of Bangladesh. [Bangladesh J Infect Dis 2014;1(1):8-11]
\end{abstract}

Keywords: Kala-azar, KAtex; Kala-azar latex agglutination test; ICT; Immunochromatographic test

[How to Cite this article: Habib ZH, Lutfor AB, Jhora ST, Ahmed I, Akhter H. Validity of KAtex Test for the Diagnosis of Kala-azar in Endemic Region of Bangladesh. Bangladesh J Infect Dis 2014;1(1):8-11]

Corresponding author: Dr. Zakir Hossain Habib, Associate Professor, Department of Microbiology, Sir Salumullah Medical College, Mitford, Dhaka, Bangladesh; Email: parashhabib@gmail.com; Cell no.: +8801711109160

Conflict of Interest: Authors have declared no conflict of interest.

Contributions to authors: $\mathrm{ZHH}, \mathrm{ABL}$, STJ have contributed from protocol preparation to manuscript writing as well as in data collection. ZHH, IA, HA have prepared and revised the manuscript as well as data analysis. 


\section{Introduction}

Visceral Leishmaniasis (VL) is a re-emerging serious public health problem in the Indian subcontinent ${ }^{1}$. The disease has been reported from 45 districts of Bangladesh ${ }^{1}$. Laboratory diagnosis of leishmaniasis can be made by demonstration of parasite in tissue of relevance by light microscopic examination of the stained specimen, in vitro culture, or animal inoculation; detection of parasite DNA in tissue samples immunodiagnosis by detecting parasite antigens and specific or nonspecific anti-Leishmania antibodies from urine and blood samples or by assay for Leishmaniaspecific cell-mediated immunity ${ }^{2-4}$. The diagnostic gold standard for VL is to confirm the presence of Leishmania species either through cultures or microscopic visualization of parasites from aspirate of bone marrow, spleen, lymph node or liver ${ }^{5}$. Though the sensitivity of splenic smears could be as high as $>95 \%,{ }^{6}$ it carries the risk of severe haemorrhage; on the other hand bone marrow aspiration is painful, cumbersome and has a low sensitivity ${ }^{6}$.Culture cannot be used for routine clinical diagnosis, as it requires expensive equipment and expertise $\mathrm{e}^{5-6}$.

On the other hand serological methods are highly sensitive and relatively non-invasive and are comparatively more suited for diagnosing VL in endemic regions ${ }^{7}$. A simple, rapid, easy to perform dipstick test using rK39 is available. Antigen detection is more specific than antibody-based immunodiagnostic tests. Latex agglutination test (KAtex) for detecting Leishmania antigen in urine of patients with VL is available. Due to the reemergence of Kala-azar in Bangladesh different diagnostic methods has to be analyzed and compared to find out a simple, field applicable rapid and reliable diagnostic method which is the mainstay to prevent the spread of the disease. So the purpose of the study was to find out the validity of a test KAtex.

\section{Methodology}

This cross sectional study was performed in the Laboratory of Department of Microbiology at Sir Salimullah Medical College, Dhaka from July 2007 to June 2008 for a period of 1 year. Patients with clinically suspected Kala-azar at different age groups with both sexes who were admitted in IPD at Sir Salimullah Medical College and Mitford Hospital, Dhaka, Mymensingh Medical College Hospital (MMCH) and Bhaluka health complex, Mymensingh were included in the study. Laboratory work was performed in the Department of Microbiology at Sir Salimullah Medical College, Dhaka and in Department of Microbiology at MMCH. Patients who have already received SAG (Sodium antimony gluconate) for treatment, or have a previous history of kala-azar were excluded from the study. With all aseptic precaution $3 \mathrm{ml}$ of venous blood was collected from each patient. Sera from 150 patients were taken for antibody detection by rK39 test strip. Approximately $5 \mathrm{ml}$ of urine sample was collected from all the patients into a clean sterile container. KAtex (Kalon Bio. UK. 2005) was done on the urine samples from all the cases. Urine sample, taken from suspected VL patient was pretreated (boiling for 5 minutes) to inactivate heat-labile materials (protein antigens) which may cause a false-positive reaction. Then $50 \mu 1$ of the treated urine sample were added to a reaction zone on the glass slide. One drop of test latex sensitized with antibodies raised against $L$. donovani antigen was then mixed with the sample on a glass slide. Both liquids were stirred to form a completely homogeneous mixture. If Leishmania was antigen present in the urine sample, it produced agglutination of the sensitized latex and after two minutes the degree of agglutination was read. Agglutination of sensitized latex indicates presence of Leishmania antigen in urine. For every assay, the negative control and positive control was done. Before collection of all the samples verbal as well as written consent was taken from the patients and/or their attendants. Ethical clearance was taken from ethical review committee. Statistical analysis was done following a standardized formula.

\section{Result}

A total number of 150 clinically suspected Kalaazar patients were recruited and rK39 ICT test was performed of which 100 cases were positive. KAtex test was done on ICT positive 100 cases of which $87.0 \%$ were KAtex positive and the rest $13.0 \%$ were KAtex negative (Table 1 ).

\section{Table 1: KAtex Positivity among study population}

\begin{tabular}{lcc}
\hline KAtex test & Frequency & Percentage \\
\hline Positive & 87 & 87.0 \\
Negative & 13 & 13.0 \\
Total & $\mathbf{1 0 0}$ & $\mathbf{1 0 0 . 0}$ \\
\hline
\end{tabular}

In this study it has been found that the sensitivity of KAtex was $87.0 \%$, specificity was $100 \%$. The PPV and NPV was $100 \%$ and $79.0 \%$ respectively (Table 2). 
Table 2: Validity Test result of KAtex

\begin{tabular}{ll}
\hline Parameters & Values \\
\hline Sensitivity & $87.0 \%$ \\
Specificity & $100 \%$ \\
Predictive value positive (PVP) & $100 \%$ \\
Predictive value negative (NVP) & $79.0 \%$ \\
\hline
\end{tabular}

\section{Discussion}

Kala-azar is always fatal if untreated $^{8-12}$. The clinical presentation of VL is not sufficiently specific to guide any treatment ${ }^{11}$. Highly accurate, cheap and simple rapid diagnostic tests are therefore crucial for case-management of $\mathrm{VL}$. Early case detection followed by adequate treatment is also important to control VL because, as yet, no vaccine is available and the long-term impact of vector control is unclear ${ }^{13}$. Since the 1980s, the main objective of VL diagnostics development has been to replace the direct demonstration of parasites in tissue smears, by a 'field test' that is more appropriate for use in a VLendemic context ${ }^{14}$. The rK39 ICT is surely promising to meet this goal. The test is easy to perform, rapid, cheap and give reproducible results. And in a suspected case in endemic area its positivity gives confirmation of Kala-azar according to the National guidelines for Kala-azar elimination in Bangladesh. Urinary Leishmania antigen is a low molecular weight heat stable carbohydrate detected in the urine of VL patients ${ }^{13-}$ ${ }^{17}$. In this study, sensitivity and specificity of KAtex was found to be $87 \%$ and $100 \%$. This test showed $100 \%$ specificity and $68 \%$ to $100 \%$ sensitivity ${ }^{15}$.

Gavgani et $\mathrm{al}^{14}$ found sensitivity of KAtex to be $77.8 \%$ and specificity $98.2 \%$ in their study. A field trial in Sudan showed that the test was positive in all 15 microscopy-positive kala-azar cases (sensitivity 100\%) and was negative in 41 of 45 (specificity $87.2 \%$ ) bone marrow and/or lymph node smear negative clinically suspected cases of kala-azar ${ }^{15}$. However, the sensitivity of this test was disappointingly low in clinically suspected patients in a VL-endemic area in Nepal ${ }^{17}$ where low sensitivity (47.4\%) against excellent specificity $(98.7 \%)$ was observed.

A significant increase in the KAtex sensitivity was found with the duration of fever, spleen size and the parasite intensity in the tissue aspirate; the first two probably reflects the duration of the illness. Parasite density is probably well-correlated with antigen load in urine ${ }^{17}$.
This study showed high sensitivity and specificity in KAtex test. Higher sensitivity may be explained by the increased parasite load of the patient as most of the patients in this country seek medical attention at later stage. Mean duration of illness before treatment is 4 months ${ }^{18}$. In this study KAtex test was done within 7 days of urine collection mostly that may also contribute to the higher sensitivity.

\section{Conclusion}

In this study KAtex test although found highly specific it lac ks in sensitivity. KAtex test may be used to confirm active cases as it detects antigen and shows high specificity. Combination of KAtex with any other serological test may be regarded as an alternative to invasive methods of Kala-azar diagnosis where facilities are inadequate.

Acknowledgement: We have acknowledged Prof. (Dr.) Akram Hossain, Professor and Head, Dept. of Microbiology, Mymensingh Medical College, Prof. (Dr.) A.K.M Shamsuzzaman, Chief Scientific Officer, IEDCR, Prof.(Dr.) S.M Shamsuzzaman Professor Microbiology, Dhaka Medical College for their continuous support and inspiration throughout the thesis work.

\section{References}

1. Jha TK. Drug unresponsiveness and combination therapy for kala-azar. Indian J Med Res 2006;123: 389-398

2. Desjeux P. Leishmaniasis: current situation and new perspectives. Comp. Immunol. Microbiol. Infect. Dis. 2004;27:305-318

3. WHO. The World Health Report [online] http://www.who. int/whr/2002/en/whr02_en.pdf(WHO, Geneva, Switzerland, 2002)

4. Hotez PJ, Remme JHF, Buss P, Alleyne G, Morel C, Breman JG. Combating tropical infectious diseases: report of the Disease Control Priorities in Developing Countries Project. Clin Infect Dis 2004;38: 871-878

5. Joshi A, Narain JP, Prasittisuk C, Bhati R, Hashim G, Jorge A, Banjara M, Kroeger A. Can viscral Leishmaniasis be eliminated from Asia. J Vector Borne Dis. 2008;45: 105111

6. Sundar S.. Diagnosis of kala-azar - an important stride. J Assoc Physicians India. 2003 Aug; 51: 753-755

7. Braz RF, Nascimento ET, Martins DR, Wilson ME, Pearson $\mathrm{RD}$, Reed SG, et al. The sensitivity and specificity of Leishmania chagasi recombinant K39antigen in the diagnosis of American visceral leishmaniasis and in differentiating active from subclinical infection. Am J Trop Med Hyg. 2002;67: 344-348

8. Chappuis F, Rijal S, Soto A, Menten J, \& Boelaert M. A meta-analysis of the diagnostic performance of the direct agglutination test and rK39 dipstick for visceral leishmaniasis. BMJ. 2006;333: 723

9. El Tai NO, El Fari M, Mauricio I, Miles MA, Oskam L, et. al. Leishmania donovani: intraspecific polymorphisms of Sudanese isolates revealed by PCR based analyses and DNA sequencing. Exp Parasitol. 2001;97: 35-44

10. Sundar S and Rai M. Laboratory Diagnosis of Visceral Leishmaniasis. Clin Diagn Lab Immun 2002; 9(5):951-958 
11. Bern C, Chowdhury R. The epidemiology of Visceral Leishmaniasis in Bangladesh: prospects for improved control. Indian J Med Res. 2006; 123:275-88

12. Desjeux P. Leishmaniasis. Public health aspects and control. Clin Dermatol. 1996;14:417-23

13. Sarkari B, Chance M and Hommel M.. Antigenuria in visceral leishmaniasis: detection and partial characterisation of a carbohydrate antigen. Acta Trop 2002; 82:339-348

14. Gavgani A.M, Shahram KhademVatan1 and Ardavan Ghazanchaei. KAtex antigen-detection test as a diagnostic tool forlatent visceral leishmaniasis cases. African J Biotech 2008; 7(7): 852-859
15. Attar ZJ, Chance ML, el-Safi S, Carney J, Azazy A, ElHadi et al.. Latex agglutination test for the detection of urinary antigens in visceral leishmaniasis. Acta Trop. 2001; 78:11-16

16. Rijall S, Boelaert M, Regmi S et. Al.. Evaluation of a urinary antigen-based latex agglutination test in the diagnosis of kala-azar in eastern Nepal. Trop Med Intern Health. 2004; 9(6): 724-729

17. Bern $\mathrm{C}$ et al. Risk Factors for Kala-Azar in Bangladesh. Emerging Infectious Diseases online. May 2005; 11( 5): Available at http://www.cdc.gov/eid 